\title{
Early recovery after surgery in elective obstetrics-gynaecology surgeries: prospective single-center pilot study
}

\author{
Ritu V. Jain ${ }^{1}$, Vaibhav Jain ${ }^{2 *}$
}

\begin{abstract}
${ }^{1}$ Department of Obstetrics and Gynaecology, Shri Mahaveer Hospital, Raipur, Chhattisgarh, India
${ }^{2}$ RIMS Medical College, Raipur, Chhattisgarh, India
\end{abstract}

Received: 30 March 2021

Revised: 01 May 2021

Accepted: 04 May 2021

\author{
*Correspondence: \\ Dr. Vaibhav Jain, \\ E-mail: bijaleejain@yahoo.com
}

Copyright: (c) the author(s), publisher and licensee Medip Academy. This is an open-access article distributed under the terms of the Creative Commons Attribution Non-Commercial License, which permits unrestricted non-commercial use, distribution, and reproduction in any medium, provided the original work is properly cited.

\begin{abstract}
Background: Enhanced recovery after surgery (ERAS) programmes employed in elective colorectal, vascular, urologic and orthopaedic surgery has provided strong evidence for decreased hospital stay without increase in postoperative complications. The aim of the study was to explore role and benefits, if any, of ERAS/ERP (early recovery protocols) implemented in patients undergoing elective obstetrics-gynaecological surgeries.

Methods: Prospective cohort of 48 consecutive patients undergoing elective obstetrics-gynaecological surgeries were included. ERP included early feeding, urinary catheter removal, mobilisation/physiotherapy, intravenous line removal and optimal oral analgesia. This was compared to control group of 50 patients undergoing similar operations prior to introduction of ERP, SPC group-standard perioperative care. Demographics and indications of surgeries were similar for both groups. The primary end-points were length of stay (LOS) and incidence of complications (Clavien-Dindo classification). Difference in means was tested using the t test assuming unequal variances. Statistical significance was defined as $\mathrm{p}<0.05$.

Results: Two groups, A (non-ERAS/SPC) and B (ERAS) were comparable with regards to demographics and indication of surgery. The mean time to solid diet, urinary catheter removal, mobilization, iv fluid removal and shift to oral analgesia was $2.57,1.13(\mathrm{p}<0.00001), 1.99,1.03(\mathrm{p}<0.00268), 1.63,1.2(\mathrm{p}<0.00001), 1.72,1.14(\mathrm{p}<0.00001)$, $1.8,1.37(\mathrm{p}<0.00001)$ days respectively. There were 31 and 21 complications in both groups, respectively $(\mathrm{p}<0.0097)$. Hospital stay was significantly shorter in the ERAS group, 2.87, 2.61 ( $\mathrm{p}<0.0378)$.

Conclusions: This pilot study shows that ERPs can be successfully implemented with significant shorter hospital stays without increase in postoperative complications in elective obstetrics-gynecology patients.
\end{abstract}

Keywords: Enhanced recovery after surgery, Enhanced recovery protocols, Standard peri-operative care, Reduced length of stay

\section{INTRODUCTION}

ERAS or ERP is a concept first described by Kehlet in early 1990s. ${ }^{1-3}$ Approach employs multimodal perioperative care pathway designed to attenuate surgical stress response and accelerate post-operative recovery. ${ }^{3-5}$ Implementation of ERPs across range of surgical disciplines has led to improved patient outcomes including reductions in post-operative complications and length of stay (LOS). Since its introduction, ERAS have been successfully used in elective gastrointestinal surgery (colorectal, hepatobiliary, gastric) and other surgical disciplines urology, vascular, thoracic, orthopaedics, benign gynaecological surgeries, gynaec-oncological surgeries. ${ }^{6-13}$ The benefits of ERAS are well established. They have shown faster physiological patient recovery, reduced LOS without an increase in complications. ${ }^{10,14}$ These benefits should be easily transferrable to obstetric- 
gynaecology patient population, if not greater, since these patients are generally younger, fitter and metabolically stable. Based on ERAS consensus guidelines, we developed and implemented an ERP for patients undergoing elective obstetrics-gynaecological surgeries. Complications were analysed and compared according to Clavein-Dindo classification.

\section{METHODS}

\section{Study details}

Prospective cohort of elective obstetric-gynaecological surgeries taken.

Group $\mathrm{A}=$ Control $(\mathrm{C})=\mathrm{SPC} / \mathrm{Non}$ ERAS $\operatorname{arm}=50$.

Group B $=$ Test $(\mathrm{T})=$ ERAS arm $=48$.

Demographics, indications were comparable.

\section{Duration of study}

Duration of study for Group A/Contol (C) / SPC/ NonERAS arm was January 2017 to August 2018 (20 months).

Duration of study for Group B/ Test (T) / ERAS arm was September 2018 to April 2020 (20 months).

\section{Test used}

The test used for this study was t test (unequal variances).

\section{Statistical significance}

A statistical significance of $\mathrm{p}<0.05$ was considered significant.

\section{Primary end-points}

LOS and incidence of complications (Clavien-Dindo classification) were the primary end-points.

\section{ERP included early}

The ERP included early were feeding, urinary catheter removal, mobilization, intravenous line removal, optimal oral analgesia.

\section{Criteria for early discharge}

The criteria for early discharge included tolerance of solid diet, pain control on oral analgesia and independent mobilization.

In our study, early feeding included starting oral sips of water within 4-6 hours of surgery, (giving chewing gum), starting of thick liquids/CHO drinks between 6-10 hours followed by soft diet by 12 hours and solid food at 24 hours of surgery. Urinary catheter was removed once patient was mobilized out of bed, at end of 18-24 hours. All patients were mobilized on first post-operative day with help of nursing staff and physiotherapists, with goal of full independence by day 2. IV fluid given as zero fluid balance policy, with emphasis on oral intake. 1.5-1 litre of maintainence IV fluids on day 1. Post-operative pain protocol consisted of tramadol infusion (up to 48 hours) paracetamol infusion (24 hours). Thereafter shifted to oral analgesia (paracetamol \pm tramadol), intramuscular diclofenac for breakthrough pain.

\section{RESULTS}

The two groups, A (non-ERAS/SPC) and B (ERAS) were comparable with regards to demographics and indication of surgery (Table 1).

When test of significance was applied for each parameter between the two groups, the differences were found to be statistically significant between them (Table 2).

There were 31 and 21 complications in SPC and ERAS groups, respectively $(\mathrm{p}<0.0097)$, showing a significant reduction in incidence of complications in ERAS group as compared to the SPC/non-ERAS group (Table 3).

The mean time to solid diet was 2.57 days in SPC arm while 1.13 days in ERAS arm $(\mathrm{p}<0.00001)$. Urinary catheter removal was done at 1.99 days in SPC arm and at end of 1.03 days in ERAS arm $(\mathrm{p}<0.00268)$. Mobilization out of bed was done at 1.63 days and 1.22 days, respectively in control and test arms $(\mathrm{p}<0.00001)$.

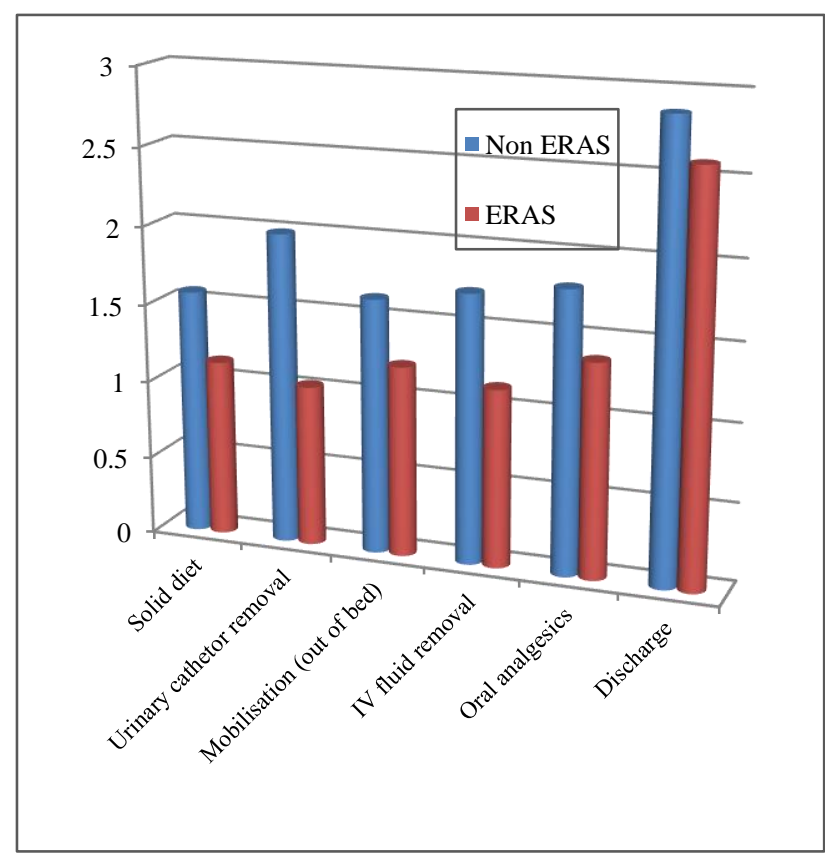

Figure 1: Comparison of various parameters between Non-ERAS/SPC and ERAS group. 
Table 1: Demographic descriptive data.

\begin{tabular}{|lll|}
\hline Demographic data & Control group (non-ERAS/SPC) & Study group (ERAS) \\
\hline Number of patients & 50 & 48 \\
\hline Type of operations-obstetric & 8 & 8 \\
\hline Gynaecology-vaginal & 12 & 16 \\
\hline Gynaecology-laparoscopic & 17 & 14 \\
\hline Gynaecology-open & 13 & 10 \\
\hline
\end{tabular}

Table 2: Effect of implementation of ERP.

\begin{tabular}{|c|c|c|c|c|c|c|}
\hline $\begin{array}{l}\text { Sr. } \\
\text { No. }\end{array}$ & Parameters & $\begin{array}{l}\text { SPC/non-ERAS } \\
(\mathrm{n}=50)\end{array}$ & $\begin{array}{l}\text { ERAS } \\
(n=48)\end{array}$ & $\mathrm{t}$ value & P value & $\begin{array}{l}\mathbf{S} / \mathbf{N} \\
\mathbf{S}^{\wedge}\end{array}$ \\
\hline 1 & Oral (solid food) ${ }^{*}$ & 2.57 & 1.13 & 5.24 & $<0.00001$ & $\mathrm{~S}$ \\
\hline 2 & Urinary catheter removal & 1.99 & 1.03 & 1.96 & $<0.00268$ & $\mathrm{~S}$ \\
\hline 3 & Mobillsation (out of bed) ${ }^{*}$ & 1.63 & 1.22 & 4.90 & $<0.00001$ & $S$ \\
\hline 4 & Intravenous fluid removal ${ }^{*}$ & 1.72 & 1.14 & 7.00 & $<0.00001$ & $\mathrm{~S}$ \\
\hline 5 & Oral analgesics* & 1.8 & 1.37 & 4.53 & $<0.00001$ & $\mathrm{~S}$ \\
\hline \multirow{4}{*}{6} & \multirow{4}{*}{ Complications $^{\#}$} & Gr $1=16$ & Gr1=11 & \multirow{4}{*}{7.07} & \multirow{4}{*}{0.00971} & \multirow{4}{*}{$S$} \\
\hline & & Gr $2=15$ & Gr2 $=10$ & & & \\
\hline & & Total $=31$ & Total $=21$ & & & \\
\hline & & $\mathrm{M}=15.5$ & $\mathrm{M}=10.5$ & & & \\
\hline 7 & Discharge $^{*}$ & 2.87 & 2.61 & 1.79 & 0.0378 & $\mathrm{~S}$ \\
\hline
\end{tabular}

${ }^{*}=$ on post of day; ${ }^{\sharp}=$ Clavien-Dindo grading; ${ }^{\wedge}=$ significant/non-significant.

Table 3: Post-operative complications.

\begin{tabular}{|c|c|c|}
\hline Clavien-Dindo grades & Non-ERAS/SPC & ERAS \\
\hline Grade 1 & 16 & 11 \\
\hline Grade 2 & 15 & 12 \\
\hline Grade 3 a and $b$ & 0 & 0 \\
\hline Grade 4 a andb & 0 & 0 \\
\hline Grade 5 & 0 & 0 \\
\hline
\end{tabular}

IV fluid removal took 1.72 and 1.14 days respectively in both arms respectively $(\mathrm{p}<0.00001)$. Shift to oral analgesia was at the end of 1.8 and 1.4 days $(\mathrm{p}<0.00001)$ in the two groups. Hospital stay was significantly shorter in ERAS group 2.6 days as compared to SPC arm which was 2.9 days $(\mathrm{p}<0.0378)$ (Figure 1$)$.

\section{DISCUSSION}

ERAS have consistently been shown to have both costrelated and patient benefits. King et al and Greco et al examined influence of ERP on clinical outcome, cost and QOL for colorectal surgery. ${ }^{15,16}$ They found $49 \%$ reduction in LOS. They also showed no transfer of costs onto another health care industry. Meta-analysis of RCTs evaluating health outcomes and resource utilization, patients adhering to ERP had reduced LOS of 2.5 days. This was reproducible improvement in quality of care by enabling standardization of health care processes. ${ }^{17}$ Similarly, our study confirms this concept with reduction in LOS of 2.6 days.
Duration of hospital stay and peri-operative morbidity and complication rate are key determinants of cost. Abdominal surgery is associated with postoperative pain, paralytic ileus, reduced pulmonary function and loss of muscle mass and function, all of which may contribute to postoperative morbidity and need for prolonged hospital stay. ERPs aims to reduce these postoperative complications by preserving normal preoperative physiology. Thus, by improving patient outcome with early discharge and reduced morbidity we are able to reduce cost of treatment.

The presence of trans-urethral catheters increase incidence of urinary tract infection and hinder patient mobilization. Urine catheters were consistently removed earlier in ERAS arm of our study after 1.03 days compared to 1.99 days in SPC arm. There was no UTI observed and all patients achieved early independent mobilization. Preservation of body composition is vital in order to reduce post-operative morbidity. Early oral nutrition with protein drinks will preserve lean body mass and maintain work performance. All our patients were started on protein drinks on post-operative day 1 and then 
stepped up to full ward diet by day 2 to 3 . Another factor shown to hinder initiation of oral intake is presence of a nasogastric tube. As per our ERP, nasogastric tubes were consistently removed early on day 1 if used. This facilitated earlier initiation of oral intake. Early optimal analgesia and early mobilization with physiotherapy are means of improving pulmonary function. Dedicated chest physiotherapy, deep breathing exercises helped. All these factors lead to earlier discharge from hospital.

Implementation of ERAS programmes are feasible as long as they are safe. The shortened LOS is of no benefit if it leads to increase incidence of post-operative complications. There were 21 complications in ERAS arm and 31 in SPC arm (significant reduction).

Meta-analyses and RCTs of ERP have shown improved routine postoperative care, reduction in length of stay, with no difference in readmissions. ${ }^{2,3}$ Significant reduction in postoperative morbidity and mortality, improvement or no change in rates of postoperative complication and readmission. ${ }^{11-14}$ Meta-analysis of surgical subspecialties confirmed cost-effectiveness. ${ }^{15}$ Data on patient satisfaction and quality of life are more limited, but available information suggests benefit. ${ }^{16-18}$ Improvements in pain scores, rapid return to baseline functional status, improved symptom scores and decreased rates of fatigue have been proven. Study of gynecologic patients found improvements in autonomy, physical complaints and postoperative pain. Schneider et al proposed to incorporate prehabilitation program (composed of exercise, nutritional support, psychological interventions) to better optimize psychophysical status of patients. ${ }^{19}$

In health care world that is increasingly focused on evidence-based medicine, resource use and measuring quality of delivered care, ERP seems natural fit across surgical specialties. The cost to implementation of ERP are few whereas benefits are tangible. As we, move towards quality metrics, bundled payments, benchmarks, and pay for performance models, ERP is the future. NHS Britain has embraced ERP as quality improvement and service tool. It considers ERP as standard of care following surgery.

Implementation of ERP is difficult as high degree of coordination is required. These interventions run counter to current practice patterns, are ingrained and difficult to change. As such, auditing and monitoring implementation is crucial to achieving success. Incidences of protocol deviation must be examined. Parameters audited should include protocol compliance and deviation, measuring clinical outcomes, QOL and satisfaction.

\section{Limitations}

The limitations we accept that our sample size is small to draw any conclusions. Prospective randomized with a bigger sample size study should investigate role and impact of ERP, particularly in emergency obstetrics. Attempts should be made to include cost effectiveness, QOL, pain, symptom and8 satisfaction scores in future studies.

\section{CONCLUSION}

Study shows ERP can be successfully implemented with significant shorter hospital stays without increase in postoperative complications. Given the fact that obstetric and gynaecological diseases remains substantial burden of disease, especially in developing countries such as India, this proven cost effective approach to patient care can be applied with no added complications, even in emergency settings.

\section{Funding: No funding sources}

Conflict of interest: None declared

Ethical approval: The study was approved by the Institutional Ethics Committee

\section{REFERENCES}

1. Kehlet H. Multimodal approach to control postoperative pathophysiology and rehabilitation. $\mathrm{Br}$ J Anaesth. 1997;78(5):606-17.

2. Carter-Brooks CM, Du AL, Ruppert KM, Romanova AL, Zyczynski HM. Implementation of a urogynecology-specific enhanced recovery after surgery (ERAS) pathway. Am J Obstet Gynecol. 2018;219(5):1-10.

3. Barber EL. Enhanced recovery pathways in gynecology and gynecologic oncology. Obstet Gynecol Surv. 2015;70(12):780-92.

4. Lassen K, Soop M, Nygren J, Cox PBW, Hendry PO, Spies C, et al. Consensus review of optimal perioperative care in colorectal surgery: ERAS Group recommendations. Arch Surg. 2009;144(10):961-9.

5. Kalogera E, Dowdy SC. Enhanced recovery pathway in gynecologic surgery: improving outcomes through evidence-based medicine. Obstet Gynecol Clin North Am. 2016;43:551-73.

6. Wind J, Polle SW, Jin PHPFK, Dejong CHC, Meyenfeldt MF, Ubbink DT, et al. Systematic review of enhanced recovery programmes in colonic surgery. Br J Surg. 2006;93(7)800-9.

7. Throop PP. Infrarenal aortic surgery with a 3-day hospital stay: a report of success with a clinical pathway. J Vasc Surg. 1999;(29):787-92.

8. Tovar EA, Roethe RA, Weissig MD, Lloyd RE, Patel GR. One-day admission for lung lobectomy: An incidental result of a clinical pathway. Ann Thorac Surg. 1998;(65):803-6.

9. Arumainayagam N, McGrath J, Jefferson KP, Gillatt DA. Introduction of an enhanced recovery protocol for radical cystectomy. BJU Int. 2008;(101):698-701.

10. Nicholson A, Lowe MC, Parker J, Lewis SR, Alderson P, Smith AF. Systematic review and 
metaanalysis of enhanced recovery programmes in surgical patients. Br J Surg. 2014;101(3):172-88.

11. Ljungqvist $O$. ERAS-enhanced recovery after surgery: moving evidence-based perioperative care to practice. JPEN. 2014;38:559-66.

12. Nelson G, Altman AD, Nick A, Meyer LA, Ramirez PT, Achtari C, et al. Guidelines for postoperative care in gynecologic/oncology surgery: Enhanced Recovery After Surgery (ERAS). Society recommendations-part II. Gynecol Oncol. 2016;140(2):323-32.

13. Nelson G, Altman AD, Nick A, Meyer LA, Ramirez PT, Achtari C, et al. Guidelines for postoperative care in gynecologic/oncology surgery: Enhanced Recovery After Surgery (ERAS). Society recommendations-part II. Gynecol Oncol. 2016;140(2):323-32.

14. Anderson ADG, McNaught CE, MacFie J, Tring I, Barker P, Mitchell CJ. Randomized clinical trial of multimodal optimization and standard perioperative surgical care. Br J Surg. 2003;(90):1497-504.

15. King PM, Blazeby JM, Ewings P, Longman RJ, Kipling RM, Franks PJ, et al. The influence of an enhanced recovery programme on clinical outcomes, costs and quality of life after surgery for colorectal cancer. Color Dis. 2006;(8):506-13.

16. Greco M, Capretti G, Beretta L, Gemma M, Pecorelli $\mathrm{N}$, Braga M. Enhanced recovery program in colorectal surgery: a meta-analysis of randomized controlled trials. World J Surg. 2014;38:1531-41.

17. Adamina M, Kehlet H, Tomlinson GA, Senagore AJ, Delaney CP. Enhanced recovery pathways optimize health outcomes and resource utilization: a metaanalysis of randomized controlled trials in colorectal surgery. Surgery. 2011;149(6):830-40.

18. Slieker J, Frauche P, Jurt J, Addor V, Blanc C, Demartines $\mathrm{N}$, et al. Enhanced recovery ERAS for elderly: a safe and beneficial pathway in colorectal surgery. Int J Colorectal Dis. 2017;32(2):215-21.

19. Schneider S, Armbrust R, Spies C, Bois A, Sehouli J, et al. Prehabilitation programs and ERAS protocols in gynecological oncology: comprehensive review. Arch Gyne Obstet. 2020; 301(2):315-26.

Cite this article as: Jain RV, Jain V. Early recovery after surgery in elective obstetrics-gynaecology surgeries: prospective single-center pilot study. Int J Reprod Contracept Obstet Gynecol 2021;10:2302-7 


\section{APPENDIX}

Table I: ERAS (present study).

\begin{tabular}{|ll|}
\hline ERAS (present study) & Counseling, education, anemia correction, anaesthesia fitness. \\
\hline Preadmission & $\begin{array}{l}\text { Prolonged fasting avoided, carbohydrate loading, fluid resuscitation, nausea, vomitting, } \\
\text { antibiotic prophylaxis commenced. }\end{array}$ \\
\hline Intraoperative & $\begin{array}{l}\text { Limited intravenous fluids (1-2 } 1 \text { crystalloids/colloids), blood products as needed, smaller } \\
\text { pfannenstiel incisions/laparoscopic approach, wherever feasible, hypothermia prevention, } \\
\text { insertion of nasogastric tube (if required) and urinary catheter, avoidance of intra- } \\
\text { abdominal drains, calf stockings, sos. }\end{array}$ \\
\hline Day of surgery & $\begin{array}{l}\text { Postoperative analgesia with tramadol infusion, intravenous paracetamol, diclofenac } \\
\text { (breakthrough pain), initiation of physiotherapy (mobilized to chair), oral fluid (at } 6 \text { hours), } \\
\text { aiming }>500 \text { ml, limit intravenous fluid (1 litre maintenance solution), subcutaneous LMW } \\
\text { heparin (thromboprophylaxis, if clinically indicated). }\end{array}$ \\
\hline Day 1 & $\begin{array}{l}\text { Urinary catheter, nasogastric tube removed, full solid oral diet, supplement nutritional } \\
\text { drinks (2-3/day until discharge), active mobilization with nursing-physiotherapy unit. }\end{array}$ \\
\hline Day 2 & $\begin{array}{l}\text { Regular oral multimodal analgesia: paracetamol (1 g } 6 \text { hourly) and tramadol (50 mg } 6 \\
\text { hourly). Intramuscular diclofenac for break-through pain only. }\end{array}$ \\
\hline Day 3-4 & $\begin{array}{l}\text { Discharged home if tolerating full solid oral diet, passing flatus/faeces, adequate pain } \\
\text { control (oral analgesia), ambulating independently, satisfactory support at home. }\end{array}$ \\
\hline After discharge & Patient given contact number, OPD follow up day 7. \\
\hline
\end{tabular}

Table II: Clavien-Dindo classification of surgical complications.

\begin{tabular}{|ll|}
\hline Grades & Includes \\
\hline $\mathbf{1}$ & $\begin{array}{l}\text { Any deviation from normal postoperative course, without need for pharmacological } \\
\text { treatment or surgical, endocopic or radiological interventions; acceptable drugs are } \\
\text { antiemetics, analgesics, antipyretics, diuretics, electrolytes, physiotherapy; includes wound } \\
\text { infections opened bedside. }\end{array}$ \\
\hline $\mathbf{2}$ & $\begin{array}{l}\text { Requiring pharmacological treatment other than grade 1. Blood transfusion, Antibiotics, } \\
\text { Total parentral Ntrition included. }\end{array}$ \\
\hline $\mathbf{3}$ & Requiring surgical, endoscopic or radiological intervention. \\
\hline $\mathbf{3 a}$ & Intervention under local/regional anaesthesia. \\
\hline $\mathbf{3 b}$ & Intervention under GA. \\
\hline $\mathbf{4}$ & Life threatening complication requiring ICU. \\
\hline 4a & Single organ dysfunction. \\
\hline $\mathbf{4 b}$ & Multiorgan dysfunction. \\
\hline $\mathbf{5}$ & Patient demise. \\
\hline
\end{tabular}

